Reply

\title{
Reply: On the Reporting of Odds Ratios and Risk Ratios, Nutrients 2018, 10, 10
}

\author{
Elena Ricci ${ }^{1, * \mathbb{D}}$, Stefania Noli ${ }^{2}$, Sonia Cipriani ${ }^{1}$, Irene La Vecchia ${ }^{2}$, Francesca Chiaffarino ${ }^{1}$, \\ Stefania Ferrari ${ }^{1}$, Paola Agnese Mauri ${ }^{1,2}{ }^{(\mathbb{C}}$, Marco Reschini ${ }^{3} \mathbb{C}^{-}$, Luigi Fedele ${ }^{1,2}$ and \\ Fabio Parazzini ${ }^{1,2}$
}

1 Dipartimento Donna-Bambino-Neonato, Fondazione IRCCS Ca' Granda Ospedale Maggiore Policlinico, 20122 Milan, Italy; son.cipriani@gmail.com (S.C.); francesca.chiaffarino@gmail.com (F.C.); stefania.ferrari@policlinico.mi.it (S.F.); paola.mauri@unimi.it (P.A.M.); luigi.fedele@unimi.it (L.F.); fabio.parazzini@unimi.it (F.P.)

2 Department of Clinical Sciences and Community Health, Università di Milano, Fondazione IRCCS Ca' Granda Ospedale Maggiore Policlinico, 20122 Milan, Italy; stefi.noli@gmail.com (S.N.); irene.lavecchia@unimi.it (I.L.V.)

3 Infertility Unit, Fondazione IRCCS Ca' Granda Ospedale Maggiore Policlinico, 20122 Milan, Italy; m.reschini@gmail.com

* Correspondence: ed.ricci@libero.it; Tel.: +39-02-55032318; Fax: +39-02-550320252

\section{Dear Editor,}

In response to the letter of Pace and Multani, in general, we cannot disagree with their considerations about the use of odds ratios, risk ratios, and rate ratios.

In the first version of the paper, our results were reported as odds ratios. Dr. Pace, one of the two reviewers, requested a new analysis more adequate to the prospective design of the study. Although all estimates were not far from unit and odds ratios were good estimates of both risk ratios and rate ratios, we agreed to that request and reported our results as rate ratios.

It was not the first time that, in the framework of assisted reproduction techniques, rate ratios have been calculated instead of risk ratios. Such a use is due to the fact that, implicitly, a cycle of ART is considered a unit of time, thus leading to the consideration of the proportion of failure or success as a rate $[1,2]$. In such a situation, rate ratios and risk ratios are equal.

The conclusions of our study did not change when we changed the analysis: Odds ratios and rate ratios for the three outcomes are reported in the Table 1. What we forgot to modify was the statistical methods, where "logistic regression" was left instead of "Cox regression". For this reason, we apologize both to the Journal and to the readers.

We should have been more explicit about these aspects of the statistical methodology, but, as the revised version was approved and published, we thought that it was clear enough. Presumably, Dr. Pace did not even see the second version, or he would have asked a further revision. 
Table 1. Odds ratios and rate ratios for the three outcomes.

\begin{tabular}{|c|c|c|c|c|c|c|}
\hline \multirow[b]{2}{*}{ Women } & \multicolumn{2}{|c|}{ Implantation } & \multicolumn{2}{|c|}{ Clinical Pregnancy } & \multicolumn{2}{|c|}{ Live Birth } \\
\hline & AOR $(95 \% \mathrm{CI})$ & $\operatorname{ARR}(95 \% \mathrm{CI})$ & AOR $(95 \% \mathrm{CI})$ & ARR $(95 \%$ CI) & AOR $(95 \% \mathrm{CI})$ & ARR $(95 \%$ CI) \\
\hline \multicolumn{7}{|l|}{ Caffeine intake } \\
\hline 1st tertile & 1 & 1 & 1 & 1 & 1 & 1 \\
\hline 3rd tertile & $0.86(0.34-2.19)$ & $0.90(0.38-2.10)$ & $0.97(0.52-1.84)$ & $1.00(0.70-1.43)$ & $0.94(0.47-1.88)$ & $0.99(0.71-1.40)$ \\
\hline$>90^{\circ}$ percentile $\S$ & $0.49(0.12-2.05)$ & $0.58(0.16-2.04)$ & $0.80(0.25-2.59)$ & $0.96(0.51-1.80)$ & $0.90(0.27-3.06)$ & $0.99(0.54-1.84)$ \\
\hline \multicolumn{7}{|l|}{ Men } \\
\hline \multicolumn{7}{|l|}{ Caffeine intake } \\
\hline 1st tertile & 1 & 1 & 1 & 1 & 1 & 1 \\
\hline 2nd tertile & $1.86(0.82-4.23)$ & $1.64(0.78-3.44)$ & $1.02(0.56-1.87)$ & $1.01(0.72-1.42)$ & $1.11(0.56-2.19)$ & $1.02(0.75-1.41)$ \\
\hline 3rd tertile & $0.74(0.29-1.92)$ & $0.78(0.32-1.87)$ & $1.28(0.68-2.43)$ & $1.07(0.76-1.52)$ & $1.02(0.51-2.05)$ & $1.00(0.72-1.40)$ \\
\hline$>90^{\circ}$ percentile $\S$ & $0.68(0.14-3.39)$ & $0.73(0.17-3.16)$ & $1.48(0.47-4.61)$ & $1.12(0.59-2.14)$ & $1.00(0.29-3.46)$ & $0.98(0.54-1.83)$ \\
\hline \multicolumn{7}{|c|}{ Combined intake (W-M) } \\
\hline Low-low & 1 & 1 & 1 & 1 & 1 & 1 \\
\hline
\end{tabular}

AOR: adjusted odds ratio; ARR: adjusted rate ratio; CI: confidence interval; W-M: women-men; $\S$ as compared to 10th percentile.

\section{References}

1. Razaz, N.; Avitan, T.; Ting, J.; Pressey, T.; Joseph, K.S. Perinatal outcomes in multifetal pregnancy following fetal reduction. CMAJ 2017, 189, E652-E658. [CrossRef] [PubMed]

2. Chen, Z.J.; Shi, Y.; Sun, Y.; Zhang, B.; Liang, X.; Cao, Y.; Yang, J.; Liu, J.; Wei, D.; Weng, N.; et al. Fresh versus Frozen Embryos for Infertility in the Polycystic Ovary Syndrome. N. Engl. J. Med. 2016, 375, 523-533. [CrossRef] [PubMed]

(c) 2018 by the authors. Licensee MDPI, Basel, Switzerland. This article is an open access article distributed under the terms and conditions of the Creative Commons Attribution (CC BY) license (http:/ / creativecommons.org/licenses/by/4.0/). 